\title{
Green House Gases, Climate Change and Enviromental Conservation for Sustainable Development
}

\author{
Isah, Yinusa \\ Department of Chemistry, Federal College of Education, \\ Okene, Kogi State, Nigeria
}

Doi:10.5901/ajis.2013.v2n6p9

\begin{abstract}
Climate change is seen as one of the greatest environmental challenges that can alter irreversibly the functioning of the earth's and could produce series of devastating effects on environmental sustainability. This paper examines the concept of the environment and conservation in relation to sustainability. Causes of climate change such as the green house gases, aerosol and land use method were discussed. Some projected impact of climate change on the Earth's environmental stability such as disruption of temperature distribution, precipitation, evapo-transpiration, clouds, air-currents and consequential shifts in the vegetation belts; melting of polar ice-caps, rise in sea level that could adversely affect low-lying areas were mentioned. Adaptation measures to the impacts of climate change were equally discussed.
\end{abstract}

Keywords: Climate change, Greenhouse Gases, Sustainability, Environment and Impact

\section{Introduction}

Our environment is being continually exploited by man in order to achieve maximum output leading not only to its degradation, but has also destabilized the physical environment. The quest of any Government is to maintain law and order, provision of basic infrastructural requirement and ensuring accelerated socio-economic development among other human needs. Each of these requires enabling social, political and physical environments. Going by scientific predictions on climate change, it has the potential to alter irreversibly the functioning of the earth's climate and to produce a series of devastating effects on environmental sustainability which will be felt worldwide.

Climate change is one of the greatest challenges facing our society today both at the international and local level like Nigeria. The debate or the causes of climate change is over as we now know that the planet is warmed largely due to human activities. Inspite of the concerted actions to stem the tide, global warming shall continued to be with us for decades to come a Even with concerted international action now, we are committed to continue global warming for decades to come. For the world to avoid disaster, the international community must work concertedly to reduce green house gas emissions which are the major known causes of global temperature rise and other environmental disasters such as extreme events including heat waves, storms, and floods and more gradual changes in the pattern of the season.

The earth's climate is changing; global temperatures are predicted to continue rising, bringing changes in weather patterns, rising sea levels and increased frequency and intensity of extreme weather events. If the temperature increases by more than $2^{\circ} \mathrm{C}$, millions of more people are expected to be at risk of coastal flooding; and $20 \%$ of species are estimated to be at increased risk 
of extinction for a warming of $1.5-2.5^{\circ} \mathrm{C}$. If temperatures rise above $4^{\circ} \mathrm{C}$ there are expected significant numbers of extinctions around the globe.

There are so many problems facing the environment which are vast and diverse. Such as global warming, the depletion of the ozone layer in the atmosphere, and destruction of the world's rain forests are just few of such problems that many scientists believe will reach critical proportions in the coming decades. All of these problems will be directly affected by the size of the human population because most of them are caused by human activities. Because of the fact that our environment has to be conserved for sustainable future generations to come we must try to recognize and address these factors that could bring about devastating effect on the environment thereby jeopardizing sustainable development. It is the concern of this paper therefore to capture the causes and impacts of climate change and make appropriate suggestions or recommendations if the future of our environment must be sustained.

\section{Conceptual Clarifications}

\subsection{The Environment}

The Environment consist of all the external factors affecting an organism which may include living organisms (biotic factors) or nonliving variables (abiotic factors), such as temperature, rainfall, day length, wind, and ocean currents. The interactions of these factors form an ecosystem. Even minute changes in any one factor in an ecosystem can influence whether or not a particular plant or animal species will be successful in its environment.

Organisms and their environment constantly interact, and both are changed by this interaction. Like all other living creatures, humans have clearly changed their environment, but they have done so generally on a grander scale than have all other species. Some of these human induced changes, such as the destruction of the world's tropical rain forests to create farms or grazing land for cattle, had altered climate patterns thereby causing global warming. In turn, altered climate patterns have changed the way animals and plants are distributed in different ecosystems (Microsoft Encarta, 2009). Scientists study the long-term consequences of human actions on the environment, while environmentalists, professionals in various fields, as well as concerned citizens advocate ways to lessen the impact of human activity on the natural environment

\subsection{Conservation}

Conservation was briefly described by the Microsoft Encarta (2009) as the sustainable use and protection of natural resources that includes plants, animals, mineral deposits, soils, clean water, clean air, and fossil fuels such as coal, petroleum, and natural gas. These resources can easily be influence by influence by climate change if there is no proper use and conservation. Because of what climate change can do to these resources there is the need for conserving them for future generation. This is because our environment is our future.

Conservation conflicts arise when natural-resource shortages develop in the face of steadily increasing demands from a growing human population.

\subsection{Sustainable development:}

This refers to a mode of human development in which resource use are aimed to meet human needs while ensuring the sustainability of natural systems and the environment, so that these needs can be met not only in the present, but also for generations yet unborn. The term 
'sustainable development' was used by the Brundtland Commission, which coined what has become the most often-quoted definition of sustainable development: it states that: "Development that meets the needs of the present without compromising the ability of future generations to meet their own needs" (United nation, 1987)

This definition contain in it two basic key concepts:

i. the concept of needs, in particular the essential needs of the world's poor, to which overriding priority should be given; and

ii. the idea of limitations imposed by the state of technology and social organization on the environment's ability to meet present and future needs.

All definitions of sustainable development require that we see the world as a system that connects space; and a system that connects time. This is the reason why the issue of climate change is a global issue because whatever happens in the western world will definitely come to affect the world around us in Africa particularly in Nigeria

\subsection{Climate change or global warming}

From the foregoing introduction, human activities have become a major force in affecting the process of climate change. Climate refers to the average weather conditions of a given geographical area studied over a period of time (usually 35 to 40 years). Parameters such as temperature, rainfall, humidity, wind (Speed and direction), evaporation, e.t.c. are used in expressing weather conditions of a place. It is when noticeable changes occur and are observed in the aforementioned parameters that, experts bring this to the notice of mankind.

Scientists on climate change have reached an overwhelming consensus that climate change is real and caused primarily by human activity. Respected scientific organizations such as the National Academy of Science, the Intergovernmental Panel on Climate Change (IPCC) and World Meteorological Association (WMO) have all identified climate change as an urgent threat caused by humans that must be addressed. The need for urgent action to address climate change is now indisputable due to the impact it has created on the environment. Our intention in this paper is to look at the causes of this climate change and its impact or effect on the sustainability of the environment.

\section{Causes of climate change or Global warming}

There are so many factors that could be said to contribute to climate change, but for convenience these factors can be group into Natural and Anthropogenic (human-induced) factors. Since the beginning of the 20th century, scientists have been observing a change in the climate that cannot be attributed to any of the 'natural' influences of the past only. This change in the climate, also known as global warming, has occurred faster than any other climate change recorded by humans is of great interest and of importance to the human population.

Among the natural causes of climate changes are;

\subsection{The green house gases (GHGs)}

These are a category of substances, which, under their gaseous state, have a greenhouse effect upon the atmosphere. By preventing infrared radiation to escape the atmosphere and they contribute immensely to the atmospheric temperature rise. These gases include the following.

1. Water vapour: The most abundant greenhouse gas (GHG), however because it spends just a short time in the atmosphere, and humans have a very impact on the amount of water in the atmosphere, it is not considered the most important GHG. 
2. Carbon dioxide $\left(\mathbf{C O}_{\mathbf{2}}\right)$ : Is a small part of the atmosphere, but one of the most important GHGs. $\mathrm{CO}_{2}$ is released naturally into the atmosphere through volcanic eruptions and animal respiration but it is also released through human activities such as deforestation and the burning of fossil fuels for energy. $\mathrm{CO}_{2}$ also spends a long time in the atmosphere increasing its impact. Since the industrial revolution, humans have increased atmospheric $\mathrm{CO}_{2}$ concentration by $30 \%$.

3. Methane $\left(\mathbf{C H}_{\mathbf{4}}\right)$ : The second most important GHG is produced both naturally and through human activities. The most significant sources of Methane come from the decomposition of organic matter e.g. in landfills and in agriculture. Another large source is from the digestion of ruminants such as cows, goats etc. Methane is a stronger GHG than $\mathrm{CO}_{2}$ because of its ability to absorb more heat; however it is much less abundant in the atmosphere.

4. Nitrous oxide $\left(\mathbf{N}_{\mathbf{2}} \mathbf{O}\right)$ : A very powerful greenhouse gas which is heavily produced in the agricultural sector, specifically in the production and use of organic fertilizers and other agricultural chemicals e.g. herbicides and pesticides. It is also produced when burning fossil fuels. Methane and nitrous oxide are 25 times and 298 times more potent than carbon dioxide respectively in terms of their potential to intensify global warming. (IPCC, 2007).

5. Chlorofluorocarbons (CFCs): These are man-made gases that were produced for industrial use, mainly as refrigerants and air conditioners. They are now regulated under the Montreal Protocol due to their adverse affect on the Ozone Layer.

Since the beginning of the 20th century industrial activity grew 40-fold, and the emissions of greenhouse gases grew 10 -fold.

The amount of $\mathrm{CO}_{2}$ in the air increased from some 280 parts per million by volume (ppmv) at the beginning of the century to $389 \mathrm{ppmv}$ at the end of 2010. The amount of $\mathrm{CO}_{2}$ varies throughout the year as the result of the annual cycles of photosynthesis and oxidation, illustrated in the graph. Similarly, methane $\left(\mathrm{CH}_{4}\right)$ rose from a preindustrial atmospheric concentration of around 700 parts per billion by volume (ppbv) to about 1,789 ppbv by 2007 .

The overall warming from 1850 to the end of the 20th century was equivalent to about 2.5 $\mathrm{W} / \mathrm{m}^{2} ; \mathrm{CO}_{2}$ contributed around 60 per cent of this figure and $\mathrm{CH}_{4}$ about 25 per cent, with $\mathrm{N}_{2} \mathrm{O}$ and halocarbons providing the remainder. This has resulted in Earth's average temperature increasing from $15.5^{\circ} \mathrm{C}$ to $16.2^{\circ} \mathrm{C}$ in the last 100 years. The warming effect that would result from a doubling of $\mathrm{CO}_{2}$ from pre-industrial levels is estimated to be $4 \mathrm{~W} / \mathrm{m}^{2}$.

\subsection{Aerosols in the Atmosphere}

Aerosols are particulates matters that are airborne which absorb, scatter and reflect radiation back into the earth. Clouds, dust and particles that can be traced to eruption due to volcanoes are good examples of natural aerosols. Burning of fossil fuels and burning of farmland used to clear forestland contribute immensely to the presence of aerosols to the atmosphere. Although aerosols are not considered a heat-trapping greenhouse gas, they do affect the transfer of heat energy radiated from Earth to space. The effect of aerosols on climate change is still being debated, but scientists believe that light-colored aerosols have a cooling effect, while dark aerosols like soot contribute to warming (Mastrandrea et al; 2008).

Aerosols in the atmosphere affect climate change by scattering and absorbing solar and infrared radiation by changing the microphysical and chemical properties of clouds. The scattering of solar radiation acts to cool the planet, while absorption of solar radiation by aerosols warms the air directly instead of allowing sunlight to be absorbed by the surface of the Earth. 


\subsection{Land use change}

Another important factor that had been identified by scientist is the way and manners by which the land is put to use.e.g. Cutting down forests to create farmland have led to changes in the amount of sunlight reflected from the ground back into space (the surface albedo). The scale of these changes is estimated to be about one-fifth of the forcing on the global climate due to changes in emissions of greenhouse gases. About half of the land use changes are estimated to have occurred during the industrial era, much of it due to replacement of forests by agricultural cropping and grazing lands over Eurasia and North America. The largest effect of deforestation is estimated to be at high latitudes where the albedo of snow-covered land, previously forested, has increased. This is because snow on trees reflects only about half of the sunlight falling on it, whereas snow-covered open ground reflects about two-thirds.

Other significant changes in the land surface resulting from human activities include tropical deforestation which changes evapotranspiration rates (the amount of water vapour put into the atmosphere through evaporation and transpiration from trees), desertification, which increases surface albedo, and the general effects of agriculture on soil moisture characteristics. All of these processes need to be included in climate models.

Except for climate change studies there are few reliable records of past changes in land use. One way to build up a better picture of the effects of past changes is to combine surface records of changing land use with satellite measurements of the properties of vegetation cover. Such analyses show that forest clearing for agriculture and irrigated farming in arid and semi-arid lands are two major sources of climatically important land cover changes. The two effects tend, however, to cancel out, because irrigated agriculture increases solar energy absorption and the amount of moisture evaporated into the atmosphere, whereas forest clearing decreases these two processes.

\section{Causes of green house gases}

There are several greenhouse gases responsible for warming the earth. These has being attributed basically to humans by emitting them in a variety of ways. Most of them come from the combustion of fossil fuels in cars, factories and electricity production. The gas responsible for the most warming is carbon dioxide, also called CO2. Other contributors include methane released from landfills and agriculture (especially from the digestive systems of grazing animals), nitrous oxide from fertilizers, gases used for refrigeration and industrial processes, and the loss of forests that would otherwise store $\mathrm{CO} 2$.

\section{Impact of climate change on the environment}

The projected impact on the Earth's environmental stability and hence changes in global climate would include: disruption of temperature distribution, precipitation, evapo-transpiration, clouds, aircurrents and consequential shifts in the vegetation belts; melting of polar ice-caps, rise in sea level that could adversely affect low-lying areas and the synergy among these discrete effects. All of these have implication for fresh water resources, agriculture and food supply, natural ecosystems, biodiversity and human health (IPCC, 1996).

Climate change has regional variations capacities for increases and decreases in the amount of rainfall resulting in floods, landslides and droughts, melting of polar ice-caps, thermal expansion, surges and acidification of oceans with resultant oceanfront flooding. The resultant natural disasters such as hurricanes, bush fires, ocean surges and landslides cause economic losses, population displacements, communal crises, forced migrations (promoting ecological refugees), desertification and widespread soil erosion /depletion effects. 
Climate change has greatly left it impact on the land and in several ways. Agriculture is extremely vulnerable to climate change. Higher temperatures can reduce yields of desirable crops while encouraging weed and pest proliferation. Changes in precipitation patterns increase the likelihood of short-run crop failures and long-run production declines. Although there will be gains in some crops in some regions of the world, but the overall impacts of climate change on agriculture are expected to be negative, threatening global food security (IFPRI, 2009). Added heat stress, shifting monsoons, and drier soils may reduce yields by as much as a third in the tropics and subtropics, where crops are already near their maximum heat tolerance (UNEP, 2001).

\section{Adaptation measures to the impacts of climate change}

Our climate will continue to change. We will have to adapt to warmer average temperatures, higher sea levels, and weather events that are more frequent and many more extreme conditions. The Intergovernmental Panel on Climate Change (IPCC) refers to adaptation practices as actual adjustments, or changes in decision environments, which might ultimately enhance resilience or reduce vulnerability to observed or expected changes in climate. Investment in coastal protection infrastructure to reduce vulnerability to storm surges and anticipated sea-level rise is an example of actual adjustments (e.g. Lagos Bar Beach Protection Scheme). The development of climate risk screening guidelines, which might make downstream development projects more resilient to climate risks, is an example of changes in the environment policy (Muthukumara et al. 2008).

Adaptation to climate risks has been viewed by Muthukumara et al., 2008 to be at three levels:

1) Responses to current variability (which also reflect learning from past adaptations to historical climates).

2) Observed medium and long-term trends in climate; and

3) Anticipatory planning in response to model-based scenarios of long-term climate change.

These measures were further classified into proactive and reactive or ex-post.

Proactive measures include:

1) Crop and livelihood diversification

2) Seasonal climate forecasting

3) community-based disaster risk reduction

4) Famine early warning systems

5) Water storage

6) Insurance

7) Supplementary irrigation and so on.

Reactive or ex-post measures: include:

1) Emergency response

2) Disaster recovery and

3) Migration.

Recent reviews indicate that the "wait-and see" or reactive approach is often inefficient and could be particularly unsuccessful in addressing irreversible damages, i.e. species extinction or unrecoverable ecosystem damages that may result from climate change.

One other adaptation strategies is keeping our forests standing so that they can provide essential environmental services like acting as carbon sinks, reservoirs of biodiversity, water catchments and regulation of climate and rain patterns. Africa and Nigeria in particular should halt unsustainable agricultural practices like Slash-and-burn, charcoal burning and removal of vegetation. We should reduce emissions from deforestation and forest degradation, because emissions from them is about 20 percent or more than what is contributed by the world transport sector put together" (Maathai, 2009). 


\section{Conclusion}

Climate change is said to take place when there is any noticeable changes in parameters such as temperature, rainfall, humidity, wind etc. when these changes are observed above a threshold level, experts will say there is climate change. This paper has critically examined the concept of the environment, conservation and sustainable development which are the major connections of this write up. Causes of climate change such as green house gases (GHGs) were discussed. Some projected impacts and adaptations measures of climate change were mentioned.

\section{Refrences}

Intergovernmental Panel on Climate Change, (IPCC). (2007). Climate change 2007: Working group 1: The physical science basis. http://www.ipcc.ch/publications_and_data/ar4/wg1/en/ch2s2-10-2.html Retrieved on 14/03/2013

International Food Policy Research Institute, IFPRI (2009). Climate change: impact on agriculture and costs of adaptation. http://www.ifpri.org/sites/default/files/publications/pr21.pdf Retrieved on $13 / 03 / 2013$

IPCC (1996). Climate change, 1995. Impacts, Adaptation and Mitigation of Climate change 1995, Impacts, Adaptation and Mitigation of Climate change. Cambridge. Cambridge University Press, England

Maathai, W. (2009). Africa; Continent Must Protect Forest to Mitigate Global Warming. The Citizen (Dar es Salaam).Distributed by All Africa Global Media (allafrica.com)

Mastrandrea, M. and Schneider, S.H. (2008). Global Warming. Microsoft Encarta (2009) [DVD]). Redmond, WA: Microsoft Corporation.

Microsoft Encarta (2009 [DVD) "Conservation." Redmond, WA: Microsoft Corporation.

Muthukumara, M.; Anil, M. and Ipe V. (2008). Climate change, adaptation and mitigation in development programs. A Practical Guide. The international bank for reconstruction \& development/The World Bank

United Nation Environmental Program, UNEP. (2001). Climate change information sheet. http://www.unep.org/dec/docs/info/ccinfokit/infokit-2001.pdf Retrieved on 13/03/2013

United Nations (1987). Report of the World Commission on Environment and Development. General Assembly Resolution 42/187, 11 December 1987. Retrieved: 2007-04-12 
